\title{
A Complete Power Demand Distribution using Renewable Electricity Generation System for India by Incorporating Solar, Wind, Thermal and Biomass Energy Resources
}

\author{
Karunya Rajha G S, Shilaja C
}

\begin{abstract}
In India the electricity demand is growing rapidly day by day due to various increasing residential, official and organizational buildings which requires more power. Electricity generation system is dominated by a hybrid renewable energy resources like wind and solar, approximately 35\% from 2007 to till now, still power shutdown is applied compulsory by the Indian Government. In order to improve the amount of power generation to $100 \%$ with increased thermal, fossil-fueled, and bio-gas power generation is converted into complete solar, wind and thermal including peaking options. In order to fulfil the demand, the wind capacity is increased from $35 \%$ into $100 \%$ by incorporating solar and thermal. Incorporating various energy systems into stand alone power grid, the highest power demand can be fulfilled. This paper applied an application for mixing various energy resource for increasing the power generation and production.
\end{abstract}

Keywords : Power Generation, Energy Demand, Renewable Energy Demand, Fuel Generation, Energy Supply.

\section{INTRODUCTION}

$\mathbf{F}$ or some time the effects of climate change in our world have become apparent, and the reserves of our new burial fuels have been reduced, causing the fuel price hikes at all times. In the meantime, $93 \%$ of the electricity in Ireland is manufactured for people, with $59 \%$ fossil fuel waste. Also, about $89 \%$ of the fuel in Ireland is imported, and it is the most severe of the current economic situation. The problem faced by Europe today is an increase in imports. Moreover greenhouse Gas (GHG) is an increase, emission, and high and unstable energy prices. Global demand for solving global $\mathrm{CO} 2$ emissions focuses on the current energy system Global Greenhouse Gas (GHG) emission of 1970 between $78 \%$ 2010. This policy points to the existing change. These energies greatly increase the range of standard power supply and increase the chance of renewal of local action plans. This is the purpose of GHG energy. The challenges of national and continental energy systems are the renewable energy supplies for future volunteer integration and balancing futures. The settings for the island, these challenges are still pronounced. All the islands in this world depend on the import of fossil fuels. This is because of the distant situation of the islands. The cost of transportation by the remote island is much

Revised Manuscript Received on December 15, 2019.

* Correspondence Author

Karunya Rajha G S, Department of EEE, Kalasalingam Academy of Research and Education, Krishnankoil, India. Email: kaaru91@ gmail.com

Shilaja $\mathbf{C}^{*}$, Department of EEE, Kalasalingam Academy of Research and Education, Krishnankoil, India. Email: shilaja.research@gmail.com higher. The price of fossil fuels has also increased. The economy of the island is also based on tourists. There is a greater impact on energy demand and structural variation. Renewable energy (RE) technologies offer a solution. And this technology provides sustainable and self-sufficient energy. However, it is possible to balance the fluctuations in mediating power supply. In order to understand the existing renewable energy sources the taxonomy is given in Figure-1.

In the past years, the North East Asian countries are stimulating economic growth and the need for fossil fuels-based energy demand. Environmental and social issues continue to increase as continuous destruction of the ecosystems worldwide has increased. Importantly, this causes a shortage of fossil fuels. In particular, this situation leads to climate change, which is affecting the growth of the country's economy. Universal Stan Completed.

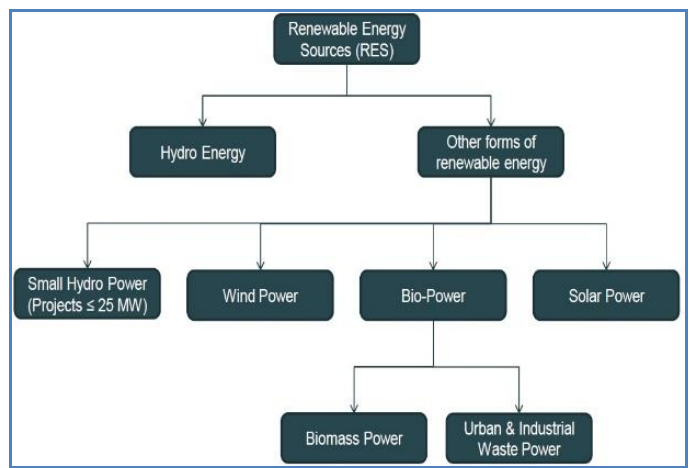

Figure-1. Taxonomy of Renewable Energy Sources

The harmful effects of coal-based air pollution should be considered for the supply of energy for entire social expenditures. These problems are $100 \%$ efficiency based on renewable energy (RE) and a universal level of competing for debate and a contrasted dispute. RE-based systems can significantly reduce the anthropogenic path using the most important RE technologies continuous strong growth and the majority of countries show their policies in the world. Displays of the highest stock-based energy systems in RE many countries and regions have already been discussed. On March 11, 2011, in Japan, a major earthquake struck on the northeast coast. Its speed is 9.0 at sea level at the Richter scale. This tsunami caused a great disaster. Furthermore, this tsunami overwhelmed the $400-\mathrm{km}-2$ land of the northeastern coast of Japan, causing more casualties.

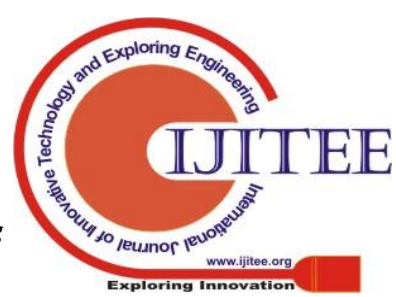


The maximum waterfall in this tsunami was $19.5 \mathrm{~m}$ in height, about $4 \mathrm{~km}$ long. The maximum run-up is $40.4 \mathrm{~m}$, making it the third largest tsunami in the last decade. Many well-designed concrete structures have been damaged by any tsunami, and many ships are shattered. Tsunami has also destroyed the security systems in Fukushima. The Dai-Ichi nuclear plant (NPP) has created a state of emergency to demolish this position. Earthquake and nuclear accident continue to be $30 \%$ of Electricity is not provided. None of the 50 nuclear plants are operating. However, many units eventually started to function.

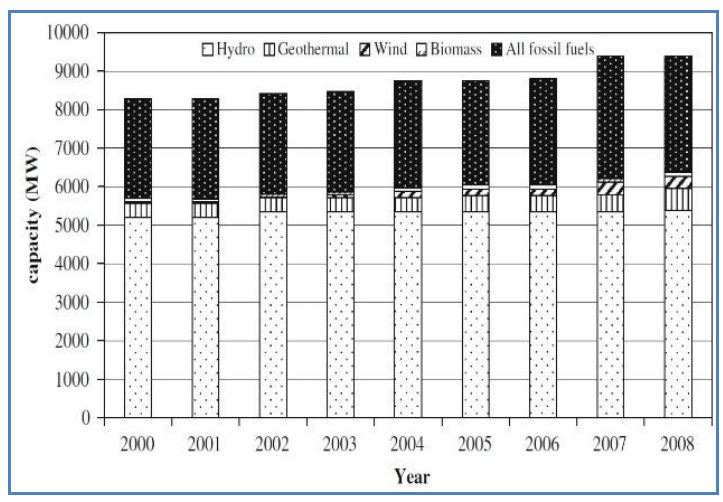

Figure.2. Operational Indian Power Generation (2000 to 2008)

Current development of the energy system simulation identifies and assesses the credibility of $100 \%$ renewable electricity for five states and the challenges posed by the Australian NEM. Global warming emissions should be reduced by 2050 . The current climate science suggests that this global gas emission should be reduced sharply. This instruction is 2GC (IPCC, 2007) prevents global warming. The International Energy Face (2011) states that, $80 \%$ of total emission emissions are permitted in 450 of its scenes for millions of views. Without any modern countries, poverty cannot be significantly reduced massive energy use, and with high returns and higher countries, the Human Development Index will be of high potential consumption. Therefore vital energy is essential for electricity, transportation or any other use. The most important aspect of Nigeria is the development of energy development and its development. Because, these privileges are a trade commodity for national revenue and it is used to support the government hopeless plan. Nigeria's energy demand increases very much. Because of the population explosion, inevitable industrialization, improving higher agricultural production and living standards. Nigeria has a large number of primary energy sources to meet current and future development needs.

\section{RELATED WORK}

Authors in [1] said that, since 2010, the most prominent national and international advocate for IPCC and the German Council for Environmental Advisers are replaced by substantial contribution to renewable energy sources for future global energy supplies, or $100 \%$ Germany, and North Africa. Some governments, such as Denmark or Germany, continued by adopting the most ambitious targets for long-term use of renewable energy sources, the European Union also finds an opportunity for Europe to provide renewable energy in 2050, a change in the initial policy of the policy that represents a fundamental pioneer. Authors in [2] described, there is no question of solutions to some of the problems solved by CCS or nuclear power, one question suggests that renewable energy sources can provide a long-term sustainable, low risk, and climate-friendly electricity, including the use of fossil fuels and nuclear energy. Energy is a limited supply source, high energy consumption, and high population Density, such as Germany, has a population of $229 \mathrm{hp} / \mathrm{km} 2$ density (F11) and power consumption of $6200 \mathrm{kWh} / \mathrm{cap}$. The solution to these two problems is that a $100 \%$ renewable power supply is a solution to the two issues, the largest contributory power generation for climate change and the remaining risk nuclear power plant operations. Authors in [3] said that, without any modern countries, poverty cannot be significantly reduced massive energy use, and with high returns and higher countries, the Human Development Index will be of high potential consumption. Therefore, vital energy is essential for electricity, transportation or any other use. The most important aspect of Nigeria is the development of energy development and its development. Because these privileges are a trade commodity for national revenue and it is used to support the government hopeless plans. Nigeria's energy demand increases very much. Because of the population explosion, inevitable industrialization, improving higher agricultural production and living standards. Nigeria has a large number of primary energy sources to meet current and future development needs. Author Rio PD (2011) [4], said that for some time the effects of climate change in our world have become apparent, and the reserves of our new burial fuels have been reduced, causing the fuel price hikes at all times. In the meantime, $93 \%$ of the electricity in Ireland is manufactured for people, with $59 \%$ fossil fuel waste. Also, about $89 \%$ of the fuel in Ireland is imported, and it is the most severe of the current economic situation. The problem faced by Europe today is an increase in imports. Moreover, greenhouse Gas (GHG) is an increase, emission, and high and unstable energy prices. Global demand for solving global $\mathrm{CO} 2$ emissions focuses on the current energy system Global Greenhouse Gas (GHG) emission of 1970 between $78 \%$ 2010. This policy points to the existing change. These energies greatly increase the range of standard power supply and increase the chance of renewal of local action plans. This is the purpose of this energy.

Authors in [5] described that, the challenges of national and continental energy systems are the renewable energy supplies for future volunteer integration and balancing futures. The settings for the island, these challenges are still pronounced. All the islands in this world depend on the import of fossil fuels. This is because of the distant situation of the islands The cost of transportation by the remote island is much higher. The price of fossil fuels has also increased. The economy of the island is also based on tourists. There is a greater impact on energy demand and structural variation. Renewable energy (RE) technologies offer a solution. And this technology provides sustainable and self-sufficient energy. However, it is possible to balance the fluctuations in mediating power supply. Authors in [6] explained, in the world, renewable energy production in Europe is growing rapidly. The European Union called its 20-20-20 goals in all countries in 2006 for renewal of $20 \%$. So far $40 \%$ of restructuring has been completed. 
In 2050, 100\% renewal will be completed. But it is expected to be the year before. $100 \%$ is still substantial uncertainty. It can be revived by the largest contribution of air circulation and PV, because the water biomass and waste resources are very low. This requires a maximum of $100 \%$ energy from the wind and sun. This requires the next generation. Stability is the main goal in today's world. We are able to obtain greater stability from the cost and efficiency of economically efficient utility. This reduces the cost of fossil fuels. In the developing world, an era of cheap fossil fuels ends due to the increase in consumers and complex political situations (oil and natural gas). In this situation, renewable energy distributed around the world is considered a standard solution. The use of renewable sources in many communities is a necessity and a special need. A report given in [7], explained a method which reduces the cost of fossil fuels. In the developing world, an era of cheap fossil fuels ends due to the increase in consumers and complex political situations (oil and natural gas). In this situation, renewable energy distributed around the world is considered a standard solution. The use of renewable sources in many communities is a necessity and a special need. Lund H. et al. [8] said that the challenges of national and continental energy systems are the renewable energy supplies for future volunteer integration and balancing futures. The settings for the island, these challenges are still pronounced. All the islands in this world depend on the import of fossil fuels. This is because of the distant situation of the islands. The cost of transportation by the remote island is much higher. The price of fossil fuels has also increased. The economy of the island is also based on tourists. There is a greater impact on energy demand and structural variation. Renewable energy (RE) technologies offer a solution. And this technology provides sustainable and self-sufficient energy. However, it is possible to balance the fluctuations in mediating power supply. Garnaut. R. (2011), stated that the Current development of the energy system simulation identifies and assesses the credibility of $100 \%$ renewable electricity for five states and the challenges posed by the Australian NEM. Global warming emissions should be reduced by 2050 . The current climate science suggests that this global gas emission should be reduced sharply. This instruction is 2GC (IPCC, 2007) prevents global warming. The International Energy Face (2011) states that, $80 \%$ of total emission emissions are permitted in 450 of its scenes for millions of views. Mori N. (2011) said that on March 11, 2011, in Japan, a major earthquake struck on the northeast coast. Its speed is 9.0 at sea level at the Richter scale. This tsunami caused a great disaster. Furthermore, this tsunami overwhelmed the 400-km-2 land of the northeastern coast of Japan, causing more casualties. The maximum waterfall in this tsunami was $19.5 \mathrm{~m}$ in height, about $4 \mathrm{~km}$ long. The maximum run-up is $40.4 \mathrm{~m}$, making it the third largest tsunami in the last decade. Many well-designed concrete structures have been damaged by any tsunami, and many ships are shattered. Tsunami has also destroyed the security systems in Fukushima. The Dai-Ichi nuclear plant (NPP) has created a state of emergency to demolish this position. Earthquake and nuclear accident continue to be $30 \%$ of Electricity is not provided. None of the 50 nuclear plants are operating. However, many units eventually started to function.

\section{A. Problem Statement and Motivation}

In this paper, the past years, India is stimulating economic growth and the need for fossil fuels-based energy demand. Environmental and social issues continue to increase as continuous destruction of the ecosystems worldwide has increased. Importantly, this causes a shortage of fossil fuels. In particular, this situation leads to climate change, which is affecting the growth of the country's economy. Universal Stan Completed. The harmful effects of coal-based air pollution should be considered for the supply of energy for entire social expenditures. These problems are $100 \%$ efficiency based on renewable energy (RE) and a universal level of competing for debate and a contrasted dispute. RE-based systems can significantly reduce the anthropogenic path using the most important RE technologies continuous strong growth and the majority of countries show their policies in the world. Displays of the highest stock-based energy systems in RE many countries and regions have already been discussed.

\section{B. Strategy Adopted}

In this paper a full integration of renewable power resources is introduced. All the wind turbines and other additional renewable energy resources are installed and integrated together. All the renewable energy resources are maintained in a same network. Also, this is possible when all the renewable energy resources are closer to all. The service support is globalised one. Most of the solar power generation companies are also converting their existing strategy into fully-integrated one.

\section{DEVELOPMENT OF POWER GENERATION}

In order to increase the power generation after investigating the impact of wind saturation in the power generation system, the renewable generation mixed. The system is built according to the following method:

1. Substitute the systems which are making problems by wind generation based on the energy generation.

2. Include any hydro scheduling, where the hydro system provides more power generation for compensating the variation in wind system.

3 . If the capacity of the other energy resources is more than $771 \mathrm{MW}$ then, the remaining energy can be generated by wind system, where it can balance the total demand in the network.

4. Like the above steps, the entire renewable energy system can add or remove the additional renewable energy resources.

$$
C V C=\left[\frac{P_{\text {fossil }}-P_{\text {backup }}}{\Delta P_{\text {wind }}}\right]
$$

Where, CVC represents the capacity value credit, $\mathrm{P} \_$fossil represents the capacity of the thermal (fossil-fuelled), 
A Complete Power Demand Distribution using Renewable Electricity Generation System for India by Incorporating Solar, Wind, Thermal and Biomass Energy Resources

P_backup is the capacity stored as backup can be added and $\llbracket \Delta \mathrm{P} \rrbracket$ _wind represents the wind power added. From the above expression, we can understand that the omitting renewable system unchanged the power generation.

$$
\begin{aligned}
& \frac{P_{\text {with }}-P_{\text {without }}}{\Delta P_{\text {wind }}}=\left[\frac{\Delta P_{\text {wind }}+P_{\text {bachup }}-P_{\text {fossil }}}{\Delta P_{\text {wind }}}\right] \\
& \frac{P_{\text {with }}-P_{\text {without }}}{\Delta P_{\text {wind }}}=\left[1+\frac{P_{\text {bachup }}-P_{\text {fossil }}}{\Delta P_{\text {wind }}}\right] \\
& 1-\frac{P_{\text {with }}-P_{\text {without }}}{\Delta P_{\text {wind }}}=\left[\frac{F_{\text {fossil }}-\text { Fackup }_{\text {back }}}{\Delta P_{\text {wind }}}\right]
\end{aligned}
$$

The results are expressed in terms of percentage (\%). Hence the CVC value of wind is represented in \%. From the basic energy generation, the $50 \%$ of the wind energy is increased by other renewable energy sources. The capacity of the total renewable energy generation is the sum of the wind power generation mixing with the other renewable energy sources. The $\%$ of the total energy generation varies in winter season due to solar, in summer season due to wind. The amount of power generation is always increased by adding various additional wind generation into the closed system according to the $\mathrm{CVC}$ value.

\section{A. Penetration of Wind}

To compare the results by calculating and employing the wind penetration using the following three equations as,

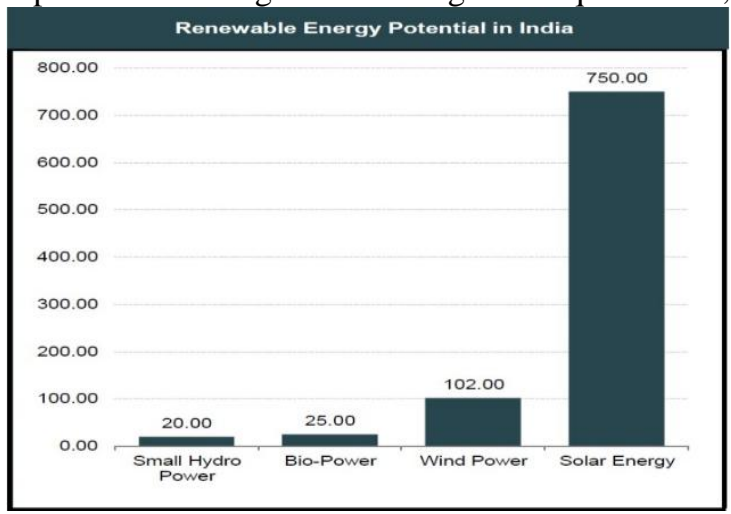

Figure.3. Potential of India in Energy Production

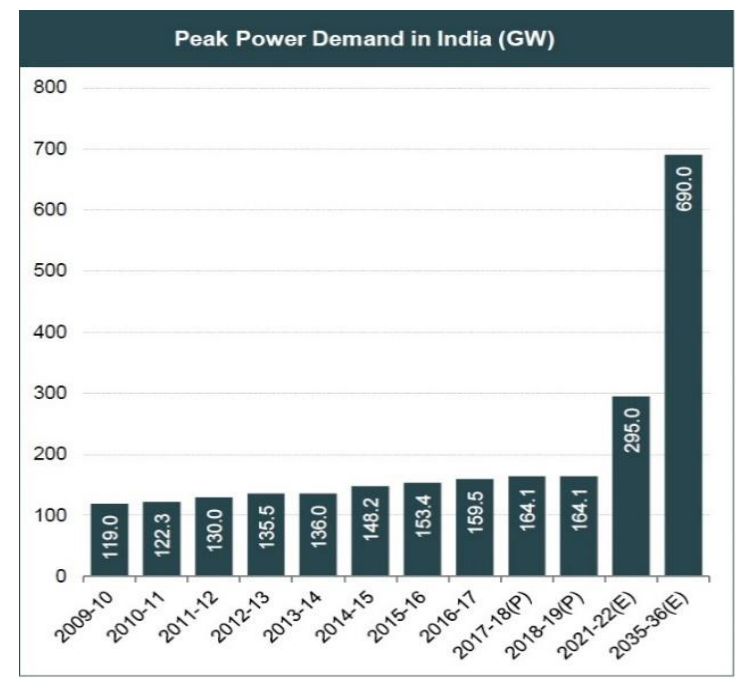

Figure.4. Changing India Towards RES

$$
\begin{aligned}
& W P(\text { installed })=\left[\frac{\text { Wind installed capacity }}{\text { total network installed capacity }}\right] \\
& W P(\text { average })=\left[\frac{\text { Annual wind energy produced }}{\text { Annual total energy demand }}\right]
\end{aligned}
$$

WP (instantaneous) $=\left[\frac{\text { Wind Power Output }}{\text { Total energy output }}\right]$

It is also noticed the definition of wind power generation from " "wind installed capacity as a percentage of peak network demand".

India estimated the potential of energy generation totally is $900 \mathrm{GW}$ from commercial sources. From the total, solar is $750 \mathrm{GW}$, Bio-energy is $25 \mathrm{GW}$, wind energy is $102 \mathrm{GW}$ and small hydro is $20 \mathrm{GW}$. From the energy generation values, it is recognised that a target of $175 \mathrm{GW}$ of renewable energy capacity will be obtained in 2022. In India the estimated potential is $8000 \mathrm{MV}$ from tidal energy, which is represented in Figure-4.

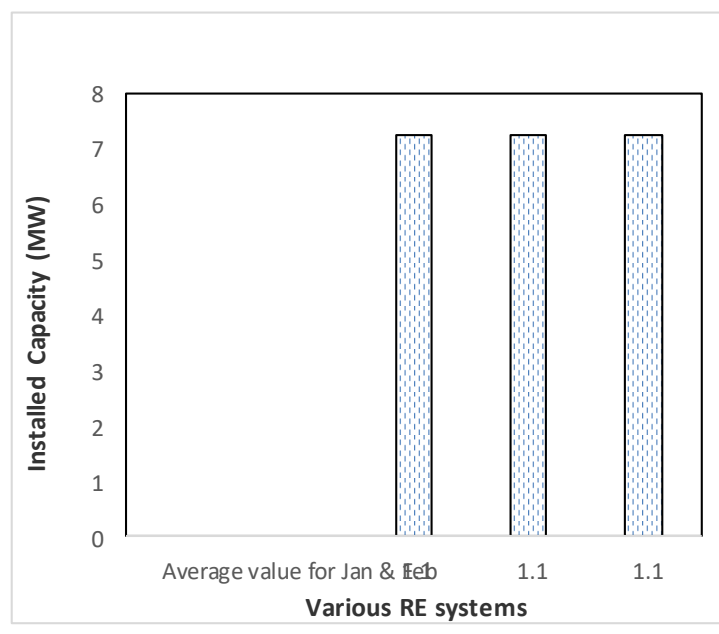

Figure-5. Installed Capacity India

From various studies obtained by a detailed literature review, it is concluded that the installed capacity and the limited capacities can fulfil the power demand in India. In this scenario only up to 2020 the power demand is predicted based on the installed capacity of the renewable energy system. It is highly impossible to fulfil the power demand without any renewable energy sources. Hence the installed capacity of the renewable energy systems is calculated and the results is given in Figrue-5. In this Figure-5, it is given that $850 \mathrm{MW}$ of thermal power, $900 \mathrm{MW}$ of Hydro power, $650 \mathrm{MW}$ of coal power1500MW of solar power and $1800 \mathrm{MW}$ of wind power is installed in India.

Though high amount of power demand is required and installed in India, based on the grid connection, bus capacities the power flow is limited in the network. 390MW of solar, $110 \mathrm{MW}$ of wind, $380 \mathrm{MW}$ of SHP, and $160 \mathrm{MW}$ of biomass is connected in the grid for power flow. It is given in Figure-6. To avoid power leakage, wastage, and reduce the cost and improve the power flow, any optimization methods are used for improving the power flow in power grid network. Similarly, the cost of the RES is calculated and given in Figure-7. 
The cost calculation is carried out for year 2016 and it is given. It is because a complete set of data can be collected from various internet sources, research articles and manufacturing units only after completion of the year. Not in the middle, start or end of the year. Hence the cost calculation is given for year 2016 and it is given in Figure-7.

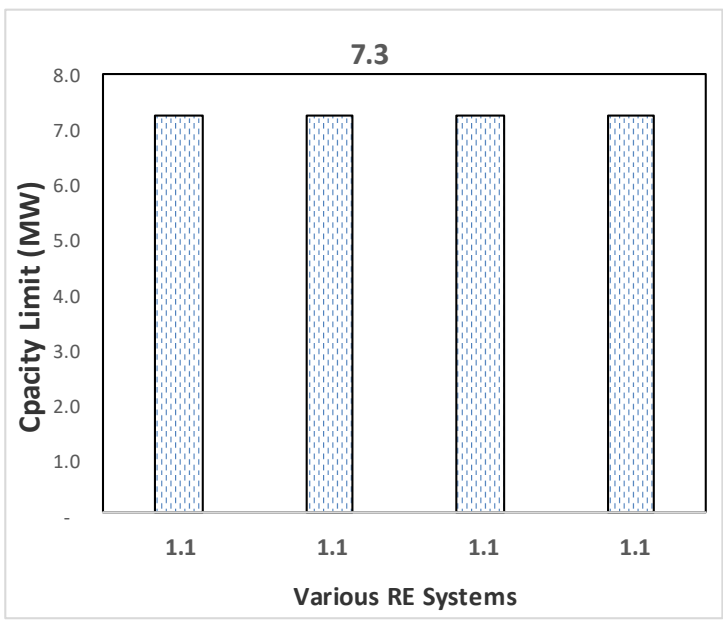

Figure-6. Limitation Capacity India

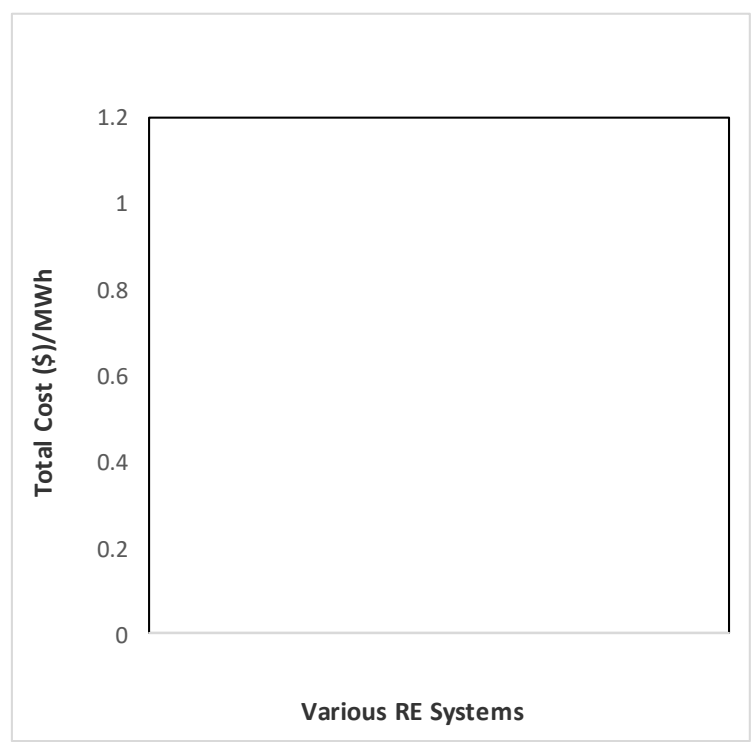

Figure.7. Year 2016 Tariff for Various RES

\section{CONCLUSION}

High amount of power generation is obtained by mixing the power generated using different renewable energy sources together in a grid or in a network. All the possible renewable energy resources are integrated for increasing the power generation where it fulfils the power demand in India. In this paper the wind power source is considered as the main source and other sources are taken as the additional sources. $50 \%$ of the energy generation is obtained from additional resources. Failure or un-success sources are replaced by wind systems. Power generation is increased mainly using wind turbine. This paper provides a fully integrated approach where it helps to integrate all the renewable energy resources. From the analytical approach the potential energy generation of India is given. The data is collected from Indian Government resources and produced. From the analytical output it is clearly noticed that the power generation is potential only by integrating all the available energy resources.

In future work the suitability of the cheapest energy resources is integrated for increasing the power generation with cost effective.

\section{ACKNOWLEDGMENT}

The authors thankfully acknowledge support from the administration, Kalasalingam Academy of Research And Education, Krishnankoil, India. The authors would like to thank the reviewers for their valuable time to review the paper and better enhancement in further.

\section{REFERENCES}

1. European Commission. Energy Roadmap 2050. (COM (2011) 885 final of 15 December 2011) Luxembourg: Publications Office of the European Union; 2012, 21. doi:10.2833/10759.

2. Federal Environment Agency, ed. Submission under the United Nations Framework Convention on Climate Change and the Kyoto Protocol 2011 National Inventory Report for the German Greenhouse Gas Inventory 1990-2009.

3. Sambo AS. Renewable energy for rural development: the Nigerian perspective. ISESCO 2005; 1:12-22.

4. Rio PD. Analyzing future trends of renewable electricity in the EU in a low carbon context. Renewable and Sustainable Energy Reviews 2011; 15 (5): $2520 \mathrm{e} 33$.

5. IPCC. Climate change 2014: synthesis report. In: Pachauri RK, Meyer LA, editors. Contribution of working groups I, II and III to the fifth assessment report of the intergovernmental panel on climate change. Geneva (Switzerland): Core Writing Team; 2014.

6. EU Commission. Commission of the European Communities: renewable energy road map: renewable energies in the 21 st century: building a more sustainable future, communication from the commission to the council and the European Parliament 848.

7. BMU-BMWi Germany. Energy concept for an environmentally friendly, reliable and affordable energy supply, https://www.bmwi.de /Redaktion/ DE /Downloads /E /energiekonzept- 2010.html.

8. Lund H, Duic N, Krajacic G, Carvalho MG. Two energy system analysis models: a comparison of methodologies and results. Energy 2007; 32(6):948-54.

9. Garnaut, R., 2011. The Garnaut Review 2011: Australia in the Global Response to Climate Change. the Cambridge University Press.

10. Mori N, Takahashi T. The 2011 Tohoku Earthquake Tsunami Join Survey Group. Nationwide Post Event Survey and analysis of the 2011 Tohoku Earthquake Tsunami. Coast Eng J (JSCE) 2011;54(1).

11. International Energy Agency. World energy outlook 2014. Paris: IEA Publications; 2014.

\section{AUTHORS PROFILE}

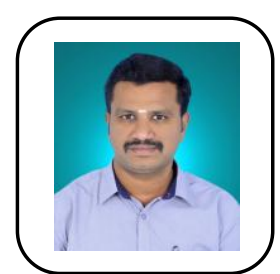

Karunya Rajha.G.S doing his Ph.D. in Electrical \& Electronics Engineering from Kalasalingam Academy of Research and Education, Krishnankovil. His M.E. in power Electronics \& Drives from Anna University in 2016 and his B.E. in Electrical and Electronics Engineering from Anna University in 2013. His research interests include Generation Expansion Planning. Power System. 
A Complete Power Demand Distribution using Renewable Electricity Generation System for India by Incorporating Solar, Wind, Thermal and Biomass Energy Resources

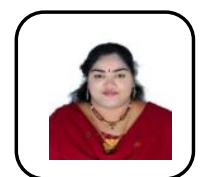

Dr.C.Shilaja is a Research Faculty in Department of Electrical and Electronics Engineering in Kalasalingam Academy of Research and Education. Now currently pursuing Post-Doctoral Fellowship from Kalasalingam Academy of Research and Education from 2018, received her Ph.D. in Power System Electrical \& Electronics Engineering from VIT University Vellore in 2018, her M.E. in Power Electronics \& Industrial Drives from Sathyabama University in 2010 and her MBA in Human Resources from Alagappa University karaikudi in 2007. Then her B.E. in Electrical and Electronics Engineering from Madras University in 2003. Her Research interests includes power system optimization, Renewable Energy, Optimal scheduling \& Power system planning. She has published 18 International Reputed Journals and 4 International conferences in these areas. 